\title{
Colleges Students' Misconception about Type of Bonding
}

\author{
Ardiansah ${ }^{1,2, *}$ \\ ${ }^{1}$ Sebelas Maret University \\ ${ }^{2}$ Indonesia Endowment Fund for Education
}

\begin{abstract}
This research is based on writer's previous misconceptions research on chemical bonding. The study aims to calculate the percentage of misconceptions and misconceptions types about chemical bonding. The method used is descriptive. Samples used in this study was 75 students in college. Data collection tool used in this study was an online modified two-tier diagnostic test. The results showed that types of student misconceptions occur in sub concept: determining the type of bonding of a compound based on the difference in electronegativity, determine the type of bonding may occur if the metal and non-metal bind together and determine two examples of ion or covalent bond compounds.
\end{abstract}

\section{Introduction}

Chemistry is one of the subjects must be taught in natural science program in Senior High School in Indonesia. Based on the ministerial decree of the ministry of education and culture about the national education system, the purpose of learning chemistry is to make the student understand about chemistry concepts and apply it to solve the problem in real life and in science and technology life. Application of chemistry in real life start with an understanding of chemistry concepts, principles, laws, and theories. But, chemistry is one of the subjects that difficult to understand by students and teachers too [1]. Most of the students hate the abstract concept that requires more attention when they learn chemistry. Furthermore, the difference between chemistry word and reality word also make a relational and interpretation problems for the students.

The knowledge level chemistry subject in senior high school can be categorized into three types, that is sub-microscopic (abstract and cannot detectable with ears, eyes, noses, tongue, and skin), macroscopic (can be detectable with our body's instrument) and symbolic (a symbol represents a chemistry formula or subject) [2-4].

The complexity of this subject also one of cause the misconception happened in chemical bonding [5]. Chemical bonding is one of difficult concept that student should understand clearly. The concept of chemical bonding also related with another concept such as thermochemistry, chemical equilibrium, and others. The lack of concept in chemical bonding will influence the next topics related each other.

Chemical bonding generally gives many conceptions in teaching and learning the process. There are several correct conceptions we cannot find in a textbook. Glynn and Duit said that the importance of teachers helps not only the commonalities among representations but also their limitations. The teachers' misconception also happened in several countries such as Indonesia [6], Turkey [7], and China [8]. They were assessed with a specific instrument to measure the number of conceptions.

A misconception is defined as a different idea, concept and subjects' thought that is different with scientific conception. The literature also called misconception as misunderstandings, nave conceptions, and alternative conceptions. Ozmen also cited that other terms of misconception is misconceptions [9-25], alternative conceptions [13, 2631], preconceptions [32-33], alternative frameworks [13, 14, 30, 34-36], nave beliefs [37], naive theories [38], naive conceptions [39], children's scientific intuitions [40], conceptual frameworks [41], children's science [42-43], common sense understanding [44], common sense concepts [45], alternative conceptual framework [25], intuitive conceptions [46], intuitive science [47], common alternative science conceptions [14] students' intuitive theories [48], prescientific conceptions [49], alternate perceptions [50], students' descriptive and explanatory systems [51] and spontaneous knowledge [52].

Misconception in a student can be detected using various detection instruments. It includes interview [53-55], open reasoning [56-57], and multiple choice [58-59]. Every instrument has different advantages and disadvantages to assess the misconception. The accuracy and precision of the result are can be represented the real if the instrument can represent the real condition in school or subject class. Multiple choice is one of the instrument can be assessed the misconception. The option should be represented the unique of conception. It must not four or five options 
every question. The option depends on the complexity of the question and opportunity of conception in the subject. The tiered instrument is a way to help more accurate result that consists of two or more tier. It mapped the conception and reduce the guess of the student. The student should choose the first tiered reason and choose the possible reason to their answer.

There were many misconceptions are found by researchers about chemical bonding reviewed by Ozmen [61], but in the type of bonding is not find in specific research. The method used were multiple choice, tiered question and interviews with some of the subjects. But, the interview cannot be recommended during the lack of time although it can detect deep insight about students' conception.

An alternative method to detect college students' understanding in a different place in Indonesia is with online with two-tier question inventories. Two tiers question consist of a multiple-choice question (2-4 options) in the first tier. The second tier is certainty of subjects' reason after answering the option that includes "Yes" for certain answer and "No" for the uncertain question. These questions were developed from previous research about the certainty of response index [62] and multiple-tiered [63]. The test used was adapted from author previous research. Distractors derived alternative conceptions may happen in the subject.

\section{Materials and Methods}

The material used in this research were adapted from author previous research. The reliability, validity, and distractor were tested and no more testing needed for this research.

Seventy-five college student of diversity educational background that got chemical bonding as their subject in senior high school. Actually, there were ninety-seven respondents participated in this survey. But, some of them wrote never got that subject in their school. They consisted of $40 \%$ of graduate students (18 to 30 years old), $49.3 \%$ master degree students (23 to
41 years old) and $10.7 \%$ from doctorate degree students ( 22 to 41 years old).

There were three type of conception in this research that is a good concept, misconception and lack of knowledge. Based on responses given, possible combinations of answer were defined. If the respondents answer correctly and stated sure, then it is possible to conclude that she/he possesses a scientific knowledge of the examined concept. We can be certain that the respondent possesses a misconception if they answer incorrectly and stated sure. Another possibility is she/he answer correctly but stated not sure then can be classified as lucky guess or lack of confidence. The last combination, incorrect-not sure, indicate a lack of knowledge.

\section{Result and Discussion}

This research includes five question established based on author previous research. In the first indicator, determining the bonding type of compound based on differences of electronegativity, two question were established. The second indicator, determine the type of bonding may occur if the metal and non-metal bind together, include one question. While the third indicator, determine two examples of ion or covalent bond compounds, consists of two question.

The question represents each indicator. First question about ionic bonding and second question about covalent bonding. The subject should use the electronegativity value to determine molecule's bonding type. The question of this indicator found in the first and second question. The third question is represented the second indicator while fourth and fifth question represents the third indicator. The fourth question about the example of ionic bonding and fifth question about the example of covalent bonding. Below is shown by Table 1 the questions and explanations of degree of conception from the subject that author got in this research.

Table 1: Five question established based on author previous research

\begin{tabular}{|c|l|}
\hline $\begin{array}{c}\text { Question } \\
\text { No }\end{array}$ & \multicolumn{1}{|c|}{ Questions } \\
\hline \multirow{4}{*}{} & $\begin{array}{l}\text { Salt or sodium chloride is formed from } \mathrm{Na}^{+} \text {and } \mathrm{Cl}^{-} \text {ions. Based on this data, the } \\
\text { type of } \mathrm{NaCl} \text { perhaps happen in this molecule after make a bonding is .... (you can } \\
\text { consider about ionic character after two ions composed to make a bonding, } \\
\text { electronegativity value for Na about } 0.93 \text { and } \mathrm{Cl} \text { about 3.16) }\end{array}$ \\
& a. Ionic bonding* \\
b. Covalent bonding \\
Are you certain with your answer? \\
a. Yes \\
b. No
\end{tabular}




\begin{tabular}{|c|c|}
\hline & $\begin{array}{l}\text { Are you certain with your answer? } \\
\text { a. Yes } \\
\text { b. No }\end{array}$ \\
\hline \#3 & $\begin{array}{l}\text { Both of } \mathrm{BeCl}_{2} \text { and } \mathrm{CaF}_{2} \text { are the example of a compound composed of metal and a } \\
\text { non-metal element. Based on this description, type of bond in these molecules is ... } \\
\text { a. Ionic bonding } \\
\text { b. Covalent bonding * } \\
\text { c. Covalent bonding and ionic bonding } \\
\text { d. Polar covalent bonding and ionic bonding } \\
\text { Are you certain with your answer? } \\
\text { a. Yes } \\
\text { b. No }\end{array}$ \\
\hline \#4 & $\begin{array}{l}\text { This pair of molecules that both of them bind by ionic bonding is ... } \\
\text { (Electronegativity value for } \mathrm{Na}: 0.93 ; \mathrm{Cl}: 3.16 ; \mathrm{H}: 2.20 ; \mathrm{Ag}: 1.93 ; \mathrm{B}: 2.04 ; \mathrm{F}: 3.98 ; \\
\mathrm{Br}: 2.96 ; \mathrm{N}: 3.04 ; \mathrm{Al}: 1.61 \mathrm{O}: 3.44 \text {. You may choose more than one option.) } \\
\text { a. } \mathrm{NaCl} \text { and } \mathrm{HCl} \\
\text { b. } \mathrm{NaCl} \text { and } \mathrm{AgCl} \\
\text { c. } \mathrm{BF}_{3} \text { and } \mathrm{KCl} \\
\text { d. } \mathrm{NaBr} \text { and } \mathrm{NH}_{3} \\
\text { e. } \mathrm{Al}_{2} \mathrm{O}_{3} \text { and } \mathrm{CsCl} \text { * } \\
\text { Are you certain with your answer? } \\
\text { a. Yes } \\
\text { b. No }\end{array}$ \\
\hline \#5 & $\begin{array}{l}\text { This pair of molecules that both of them bind by covalent bonding is } \ldots \\
\text { Electronegativity value for } \mathrm{Na}: 0.93 ; \mathrm{Cl}: 3.16 ; \mathrm{H}: 2.20 ; \mathrm{Ag}: 1.93 \mathrm{~B}: 2.04 ; \mathrm{F}: 3.98 ; \mathrm{Br} \text { : } \\
\text { 2.96; } \mathrm{N}: 3.0 ; \mathrm{Al}: 1.61 ; \mathrm{O}: 3.44 \text {. You may choose more than one option. } \\
\text { a. } \mathrm{NaH} \text { and } \mathrm{AgCl} * \\
\text { b. } \mathrm{HBr} \text { and } \mathrm{KCl} \\
\text { c. } \quad \mathrm{NaCl}^{*} \text { and } \mathrm{H}_{2} \mathrm{O} \\
\text { d. } \mathrm{NH}_{3} \text { and } \mathrm{AlF}_{3} \\
\text { e. } \quad \mathrm{BH}_{3} \text { and } \mathrm{NaBr} \\
\text { Are you certain with your answer? } \\
\text { a. Yes } \\
\text { b. No }\end{array}$ \\
\hline
\end{tabular}

There was one misconception type occurred in this question. While two type lack of knowledge. $76 \%$ of the subject was chosen ionic bonding when they asked about the type of bonding in sodium chloride molecules. It can be accepted because almost all of literature in chemistry textbook write sodium chloride as their examples for ionic bonding. Furthermore, the subject also remembers this concept all along their life. Previous research said the subject spontaneously answer the question without further thinking when they found this question. They also did not use the electronegativity value written in question ion from metal $\left(\mathrm{Na}^{+}\right)$and ion from non-metal $\left(\mathrm{Cl}^{-}\right)$will compose ionic bonding.

Only $5.3 \%$ subject certainly chosen sodium chloride is covalent bonding as their answer. This subject can be categorised as a misconception. They can be simplified as forgot the right concept. It same with another research. This is different with science concept that a compound can be categorised an ionic bonding if they have a difference of electronegativity value more than 1.7 [64]. The electronegativity differences between $\mathrm{Na}$ (electronegativity value: 0.93 ) and $\mathrm{Cl}$ (electronegativity value: 3.16 ) is 2.23. This value shows that sodium chloride is ionic bonding when bond each other.

While $18.6 \%$ chosen the answers uncertainty for this question. It consists of $13.3 \%$ uncertain chosen ionic bonding and 5.3\% uncertain chosen covalent bonding as type bonding of sodium chloride. It means the subject in this research cannot remember they have gotten in previous school degree although more than half of them remember.

The scientific concept of this problem is based on Effendy's book entitled "Ikatan Kimia (Chemical Bonding)". A molecule calls have a covalent bonding if the difference of electronegativity value between atom formed is lower than 1.7 in Pauling Scale. Zinc sulphide consists of $\mathrm{Zn}$ which is 1.65 value of electronegativity while $\mathrm{S}$ is 2.58 so that the electronegativity value differences is 0.93 . It indicates that zinc sulphide is formed by covalent bonding.

This question captured student conception about this problem. Almost a quarter of them knows the right concept about covalent bonding. There was a misconception type occurred in this problem, while two type lack of knowledge. $21.3 \%$ subject was chosen ionic bonding when they answered about the type of bonding in zinc sulphide molecules. It means they know the concept of covalent bonding without any uncertainty.

$40 \%$ of subject indicated as a misconception. It similar to author's previous research [65]. Some of the subjects only decided the type of bonding based on metal and non-metal characteristics. They directly answer the question without further thinking when they 
found this question. They also did not use the electronegativity value written in question.

While $38.7 \%$ chosen the answers uncertainty for this question. It consists of $20 \%$ uncertain chosen ionic bonding and $18.7 \%$ uncertain chosen covalent bonding as type bonding of zinc sulphide. It means the subject in this research is not enough knowledge for this problem.

Subject conceptions' regarding the determination of the type of bonding that may occur between metallic and non-metallic elements in a molecule. Subjects were asked to specify the type of bonding in compounds $\mathrm{BeCl}_{2}$ and $\mathrm{CaF}_{2}$. The conception of scientists' topic is based on the ionic characteristic, metallic and nonmetallic elements can form compounds that bind covalently-ion and depends on the percentage of ionic character. Binary compound that has more than 1.7 electronegativity difference will form compounds that bind ions whereas the compound having electronegativity difference of less than 1.7 will form polar covalent compounds. $\mathrm{BeCl}_{2}$ compound has the electronegativity difference of 1.5 while $\mathrm{CaF}_{2}$ compound electronegativity difference of 3.0 so as to have an ionic bond.

In the first option that mentions the type of $\mathrm{BeCl}_{2}$ and $\mathrm{CaF}_{2}$ is ionic bonding chosen by $36 \%$ of the subject. It consists of $28 \%$ certain with their answer and $8 \%$ uncertain answer this option as their answer. Like previous research, the subject may believe that every element of metal and non-metal will definitely form ionic bonds. They spontaneously answer ionic bond when it finds a molecule concerning the determination of the type of bonding between metallic and non-metallic elements without further thinking. Some of the literature of chemistry textbook in senior high school write this manner to determine the type of bonding.

The scientist conception, B option, only chosen by $17.3 \%$. It consists of $9.3 \%$ certain and $8 \%$ uncertain when they chose this answer. This means less than $10 \%$ is understanding the correct conception about not all the metallic and non-metallic element form ionic bonding. This conception that not all of student understand though it sometimes beryllium chloride wrote in the textbook as covalent bonding. It caused by the example about beryllium chloride never mention as metal and non-metal element. They associated the calcium fluoride formed by ionic bonding too similar as beryllium chloride.

The third and fourth option can be combined because of looks similar which almost a half of subject chosen this answer. As 24\% and 22.7\% were chosen this option. The "C" option chosen by $10.7 \%$ certainty subject and $13.3 \%$ uncertainty subject while the "D" option chosen by $10.7 \%$ certainty subject and $12 \%$ uncertainty subject. This mean subject understood the type of beryllium chloride that sometimes appear in chemistry textbook as covalent bonding, but they did not understand the calcium difluoride bonding type and associated as ionic bonding. It caused by both calcium and fluoride were known as reactive and located in metal and non-metal elements.
In previous research author [65] also found five type of misconception as follow: (1) the subject looked at bonding that occurs when metallic and non-metallic elements bonded by a large electronegativity difference without specify the value of the difference in electronegativity to form ionic bonds, (2) the subject is only looking at ionic bonds based on the properties of metals and non-metals without using the data value of the difference in electronegativity in determining the type of bonding compound, (3) the subject considers the compound $\mathrm{BeCl}_{2}$ two $\mathrm{Cl}$ atoms attract electrons from the atoms $\mathrm{Be}$, whereas $\mathrm{CaF}_{2}$ compound $\mathrm{F}$ atom attracts two electrons from an atom $\mathrm{Ca}$. $\mathrm{Cl}$ atoms and $\mathrm{F}$ will be a negative ion is $2 \mathrm{Cl}^{-}$and $2 \mathrm{~F}^{-}$, (4) the subject considers $\mathrm{BeCl}_{2}$ formed from two elements $\mathrm{Be}^{2+}$ and $\mathrm{Cl}$ while $\mathrm{CaCl}_{2}$ is formed of two elements of $\mathrm{Ca}^{2+}$ and $\mathrm{Cl}$, (5) the subject assumes that the ionic bonds occur in $\mathrm{BeCl}_{2}$ and $\mathrm{CaCl}_{2}$ compound which is metallic and nonmetallic elements causing electrostatic forces.

In the third indicator, determine two examples of ion or covalent bond compounds, two question were established. First question about ionic bonding and second question about covalent bonding. Both of question made with previous author research about chemical bonding topic [65]. But, the subject used here is different with another chemistry teacher instrument and some of the modifications has made. The subject should use the electronegativity value to determine molecule's bonding type. The first question translation show above:

Subject conceptions' regarding the determination of sample molecules that bind to ionic bonding in a molecule consist of 56 subjects chosen a single answer for the question and 19 subjects chosen more than one answer. In this question, the subject asked to specify examples of compounds that bind ionic bonding. The subject was allowed to choose one or more answer in this question. The conception of scientists in this matter is a binary compound that has more than 1.7 electronegativity difference will form compounds that bind ionic compound. The $\mathrm{Al}_{2} \mathrm{O}_{3}$ has an electronegativity difference 2.0 and the $\mathrm{CsCl}$ has an electronegativity difference 2.4 so that the ionic bonds occur in the compounds $\mathrm{Al}_{2} \mathrm{O}_{3}$ and $\mathrm{CsCl}$ [64].

Only a person or $1.8 \%$ subject certainly was chosen aluminium oxide and caesium chloride as an example of ionic bonding. This mean very small amount of subject understand and can determine a pair of the compound in ionic bonding. He/she using difference value of atomic compiling based on electronegativity value each. Another two people (3.6\%) were chosen this option with the uncertainty that means they are got a lucky guess or uncertain with their choice.

In the other hand, another option is dominated by subject. The first option, sodium chloride and hydrochloride acid were chosen by about a quarter of subject. It can be accepted because both of them is consists of IA and VIIA groups. Some people assume that this group will make an ionic bonding when two atoms bind a molecule. It similar with author previous research that subject did not use the data value of the 
difference in electronegativity compounds in determining the type of bond despite having been supplied electronegativity value compound constituent elements. They were thought the formation of ionic bonds based on the position of the element in Table of Element Periodic.

Most of the subject were chosen sodium chloride and silver (I) chloride as an example of ionic bonding. They include $37.5 \%$ of the subject. Previous research said that subject assumed the properties of metals and non-metals of an element and by anion and cation will form an ionic bond. This is not in accordance with the conception of scientists who claimed that the binary compound that has more than 1.7 electronegativity difference will form compounds that bind ions [64]. Electronegativity value of $\mathrm{Na}(0.93)$ and $\mathrm{Cl}(3.16)$, then the difference in electronegativity is 2.23 . This value indicates that the compound has the sodium chloride ionic bond after binding [64]. However, silver (I) chloride compounds have an electronegativity difference of 1.07 , so it has the properties of a polar covalent bond.

Three people were certainly chosen $\mathrm{c}$ and d option as their answer. The $\mathrm{c}$ option, $\mathrm{BF}_{3}$ and $\mathrm{KCl}$, chosen by two people and the option $\mathrm{d}, \mathrm{NaBr}$, and $\mathrm{CH}_{3}$ chosen by a person as their answer. Unlike previous option, this option chosen by fewer people. It caused by the molecules is unfamiliar. Also, each one person chose these options as uncertainty answer. As a conclusion, their conception in about this question is rarely found. This categorised as minority chosen by subject.

There were 19 people chosen more than one option as their answer count separately. Most answer chosen by subject is $\mathrm{NaCl}, \mathrm{HCl}$ and $\mathrm{AgCl}$ as molecules bind by ionic bonding about $26.3 \%$. The second choice most chosen is $\mathrm{NaCl}, \mathrm{AgCl}, \mathrm{BF}_{3}$ dan $\mathrm{KCl}$ about $15.8 \%$. While other option: $\mathrm{NaCl}, \mathrm{AgCl}, \mathrm{Al}_{2} \mathrm{O}_{3}$ and $\mathrm{NH}_{4} \mathrm{Cl}$; $\mathrm{NaCl}, \mathrm{HCl}, \mathrm{BF}_{3}$ and $\mathrm{KCl} ; \mathrm{NaCl}, \mathrm{HCl}, \mathrm{AgCl}, \mathrm{Al}_{2} \mathrm{O}_{3}$, and $\mathrm{NH}_{4} \mathrm{Cl}$; and $\mathrm{NaCl}, \mathrm{HCl}, \mathrm{AgCl}, \mathrm{BF}_{3}$ and $\mathrm{KCl}$, chosen by a person each. It also consists of uncertainty answer: $\mathrm{NaCl}, \mathrm{HCl}, \mathrm{Al}_{2} \mathrm{O}_{3}$, and $\mathrm{NH}_{4} \mathrm{Cl} ; \mathrm{NaCl}, \mathrm{AgCl}, \mathrm{BF}_{3}$, and $\mathrm{KCl} ; \mathrm{NaCl}, \mathrm{HCl}, \mathrm{Al}_{2} \mathrm{O}_{3}$, and $\mathrm{NH}_{4} \mathrm{Cl} ; \mathrm{NaCl}, \mathrm{HCl}, \mathrm{AgCl}$, $\mathrm{BF}_{3} \mathrm{KCl}, \mathrm{NaBr}$, and $\mathrm{NH}_{3}$; was also chosen by a people. They dominant uncertainty chose $\mathrm{NaCl}, \mathrm{HCl}$, and $\mathrm{AgCl}$ as their answer about $15.8 \%$. This data captured the conception happen in the subject was based on metal and non-metallic element only.

Previous research captured that these conceptions caused by: (i) Subject only looking at compounds that bind to ions formed from metal and non-metal elements to the compound. They will answer ionic bond is formed by metal and non-metal elements that spontaneously when they find a compound concerning the determination of the type of bonding between metallic and non-metallic elements without thinking about the truth and electronegativity differences value. (ii) They view about of the positive ions and negative ions form ionic bonds in compounds. They only looked that the bonds between the elements that form the anion and cation will have an ionic bond. This is different with scientist concept that there are several compounds that are formed by ions can form covalent bonds [64] (iii) Compounds are formed from metal and non-metal elements which have a large electronegativity difference. Subject's explanations that assume that every element of metal and nonmetallic elements to form ionic bonds because it has a large electronegativity difference regardless of data values electronegative constituent elements of a compound.

Subject conceptions' regarding the determination of sample molecules that bind to covalent bonding in a molecule consist of 62 subjects chosen a single answer for the question and 13 subjects chosen more than one answer. In this question, the subject asked to specify examples of compounds that bind covalent bonding. The subject was allowed to choose one or more answer in this question. The conception of scientists on this matter binary compounds that have an electronegativity difference of less than 1.7 will form covalent bonds with polar compounds [64]. Both compounds have an electronegativity difference of less than 1.7 , ie $\mathrm{NaH} 1.2$ and $\mathrm{AgCl}$ of 1.07 so that couples covalently bonded compounds are $\mathrm{NaH}$ and $\mathrm{AgCl}$. [64].

This question has several conceptions captured. $6.5 \%$ of the subject was certainly given sodium hydride and silver (I) chloride for their answer as an example of covalent bonding. This is mean only small of the subject can understand and determine a pair of a compound bind by covalent bonding. There was $11.3 \%$ of subject uncertainly chosen this option as their answer which means they got a lucky guess with their answer.

In the other side, " $D$ " option is more chosen by subject. $37.1 \%$ subject certain and $19.4 \%$ uncertain chosen $\mathrm{NH}_{3}$ and $\mathrm{AlF}_{3}$ bind by covalent bonding. It indicated that result in this research same with previous author research. Their reason this option at least caused by: (1) Subject are only looking at the compound ammonia covalent bonds due to the sharing of a pair of electrons without specifying the type of bond on aluminium fluoride. However, they associate that aluminium fluoride compounds have the same kind of bond with the compound ammonia is a covalent bond. (2) Both of ammonia and $\mathrm{AlF}_{3}$ are derived from nonmetallic elements. Subject associate Al including metallic elements will form covalent bonds with the elements. This is contrary to scientist conception that aluminium fluoride is ionic bonding. The differences electronegativity between $\mathrm{Al}$ and $\mathrm{F}$ about 2.37 so that make aluminium fluoride has ionic bonding. The "B", and "E" option chosen by a fewer subject while the "C" option was chosen by nobody. The "B" option, $\mathrm{HBr}$ and $\mathrm{KCl}$ as an example of covalent bonding, was chosen by $6.5 \%$ of the subject. This mean they do not understand the potassium chloride bind by covalent bonding they did not consider the electronegativity difference for this problem. Only a person chose the option "E". Like previous option, they have a similar problem occurred.

There were 13 people chosen more than one option as their answer count separately. Three people answer chosen $\mathrm{NH}_{3}, \mathrm{AlF}_{3}, \mathrm{BH}_{3}$ and $\mathrm{NaBr}$ as another person chose $\mathrm{HBr}, \mathrm{KCl}, \mathrm{NaCl}$ and $\mathrm{H}_{2} \mathrm{O}$ as their answer. It also 
consists of uncertainty answer: $\mathrm{NaCl}, \mathrm{H}_{2} \mathrm{O}, \mathrm{NH}_{3}$ and $\mathrm{AlF}_{3} ; \mathrm{HBr}, \mathrm{KCl}, \mathrm{BH}_{3}$ and $\mathrm{NaBr} ; \mathrm{NaCl}, \mathrm{H}_{2} \mathrm{O}, \mathrm{NH}_{3}$ and $\mathrm{AlF}_{3}$; $\mathrm{NaH}, \mathrm{AgCl}, \mathrm{HBr}, \mathrm{KCl}, \mathrm{NaCl}, \mathrm{H}_{2} \mathrm{O}, \mathrm{NH}_{3}, \mathrm{AlF}_{3}$, $\mathrm{BH}_{3}$ and $\mathrm{NaBr}$; $\mathrm{NaH}, \mathrm{AgCl}, \mathrm{NaCl}$ and $\mathrm{H}_{2} \mathrm{O}$; was also chosen by a people (7.7\%). They dominant uncertainty chose $\mathrm{NaCl}, \mathrm{H}_{2} \mathrm{O}, \mathrm{NH}_{3}$ and $\mathrm{AlF}_{3}$ was chosen by two people and $\mathrm{NH}_{3}, \mathrm{AlF}_{3}, \mathrm{BH}_{3}$ and $\mathrm{NaBr}$ was chosen by three people. This data captured the conception happen in the subject was based on metal and non-metallic element only.

The conclusion of this research was found many types of misconception happen in the subject about determination the type of bonding using two-tier diagnostic test. The subjects understand the proper concepts that written in chemistry textbook only. They did not use the electronegativity value to determine the bonding type. Thus, metallic characteristic was a popular concept used by subjects when considering the type of bonding in a molecule.

Below is shows the Table 2, the summary of conception found.

Table 2. Subject Conception Summary about Type of Bonding in Molecules.

\begin{tabular}{|c|c|c|}
\hline $\begin{array}{c}\text { Item } \\
\text { No }\end{array}$ & Subjects' Conception & $\%$ \\
\hline$\# 1$ & Sodium chloride bind by covalent bonding while making a molecule & $5.3 \%$ \\
\hline$\# 2$ & Zinc sulphide is binding from ionic bonding & $40 \%$ \\
\hline$\# 3$ & $\begin{array}{l}\text { a. The bonding types' of } \mathrm{BeCl}_{2} \text { and } \mathrm{CaF}_{2} \text { is ionic bonding } \\
\text { b. The bonding type of beryllium chloride is covalent bonding, calcium } \\
\text { difluoride bonding type bind ionic bonding. }\end{array}$ & $\begin{array}{l}28 \% \\
10.7 \% \\
(10.7 \%)\end{array}$ \\
\hline \#4 & $\begin{array}{l}\text { a. Sodium chloride and hydrochloride acid were binds by ionic bonding } \\
\text { b. Sodium chloride and silver (I) chloride as an example of ionic bonding. } \\
\text { c. } \mathrm{BF}_{3} \text { and } \mathrm{KCl} \text { are the examples of ionic bonding. } \\
\text { d. } \mathrm{NaBr} \text { and } \mathrm{CH}_{3} \text { are the examples of ionic bonding } \\
\text { e. } \mathrm{NaCl}, \mathrm{HCl}, \text { and } \mathrm{AgCl} \text { is molecules bind by ionic bonding } \\
\text { f. } \mathrm{NaCl}, \mathrm{AgCl}, \mathrm{BF} \text { and } \mathrm{KCl} \text { is molecules bind by ionic bonding }\end{array}$ & $\begin{array}{l}25 \% \\
37.5 \% \\
1.8 \% \\
1.8 \% \\
26.3 \% \\
15.8 \%\end{array}$ \\
\hline$\# 5$ & $\begin{array}{l}\text { a. The } \mathrm{NH}_{3} \text { and } \mathrm{AlF}_{3} \text { molecule bind by covalent bonding. } \\
\text { b. The } \mathrm{HBr} \text { and } \mathrm{KCl} \text { molecule bind by covalent bonding. } \\
\text { c. The } \mathrm{NH}_{3} \text { and } \mathrm{NaBr} \text { molecule bind by covalent bonding. } \\
\text { d. The } \mathrm{NH}_{3}, \mathrm{AlF}_{3}, \mathrm{BH}_{3} \text { and } \mathrm{NaBr} \text { are molecules bind by covalent bonding. } \\
\text { e. The } \mathrm{HBr}, \mathrm{KCl}, \mathrm{NaCl} \text { and } \mathrm{H}_{2} \mathrm{O} \text { molecules bind by covalent bonding. }\end{array}$ & $\begin{array}{l}37.1 \% \\
6.5 \% \\
1.6 \% \\
23.1 \% \\
7.7 \%\end{array}$ \\
\hline
\end{tabular}

This work was supported by Indonesia Endowment Fund for Education from the Indonesia Ministry of Finance. Any opinions, findings, and conclusions or recommendations expressed in this material are those of the authors and do not necessarily reflect the views of the Indonesia Ministry of Finance

\section{References}

1. M. B. Nakhleh, J. Chem. Edu. 69, 191-196 (1992)

2. D. Gabel, J. Chem Edu, 76(4), 548-554 (1999)

3. J. K. Gilbert, D. Treagust, Multiple representations in chemical education. (The Netherlands: Springer, 2009)

4. A. H. Johnstone, Sch. Sc. Rev., 64, 377-379 (1982)

5. A. K. Griffiths, K. R. Preston, J. Res. Sc. Teach., 29, 611-628 (1992)

6. Ardiansah, E. Enawaty, I. Lestari, J. Pendidikan dan Pembelajaran Untan, 3(9), 1-18 (2014)

7. Kolomuç, Tekin, Eura. J. Phys. Chem. Educ., 3(2), 84-101, (2011)

8. Cheung, Ma, Yang, Int. J. of Sc. Maths. Edu., 7(6), 1111-1133 (2009)

9. I. O. Abimbola, Sc. Edu., 72, 175-184 (1988)

10. D. E. Brown, J. of Res. Sc. Teach. 29, 17-34 (1992)
11. S. K. Chambers, T. Andre, J. Res. Sc. Teach., 34, 107-123 (1997)

12. Y. Din, J. Bio. Edu. 33, 21 (1998)

13. R. Driver, J. Easley, St. Sc. Ed., 5, 61-84 (1978)

14. F. M. Gonzalez, Sch. Sc. Maths. 97,68 (1997)

15. A. K. Griffiths, Proceedings of the 1994 International Symposium on Problem Solving and Misconceptions in Chemistry and Physics, (The International Council of Association for Science Education Publications, 70-99, 1994)

16. A. K. Griffiths, K. Thomey, B. Cooke, G. Normore, J. Res. Sc. Teach., 25, 709-719 (1988)

17. H. Helm, Phys. Edu., 15, 91-97 (1980)

18. P. W. Hewson, M. G. Hewson, Inst. Sc,, 13, 1-13 (1984)

19. A. E. Lawson, L. D. Thompson, J. Res. Sc. Teach., 25, 733-746 (1988)

20. J. Michael, Adv. Physio. Edu., 26, 5-6 (2002)

21. M. B. Nakhleh, J. Chem. Edu.,69,191-196 (1992)

22. J. Nussbaum, Int. J. Sc. Edu., 3, 159-169 (1981)

23. S. J. Sanger, Sc. Edu., 81, 123-135. (1997)

24. K. S. Taber, J. Sc.Edu., 20,597-608 (1998)

25. L. R. Astudillo, M. Niaz, J. Sc. Edu. Tech., 5, 131-140 (1996)

26. J. Gilbert, D. Swift, Sc. Edu., 69, 681-696 (1985)

27. M. Niaz, J. Sc. Edu. Tech., 10, 205-211 (2001)

28. D. Palmer, Int. J. Sc. Edu., 23, 691-706 (2001) 
29. K. S. Taber, Chem. Edu.: Res. Prac. Euro., 2, 4351. (2001)

30. H. Wandersee, J. J. Mintzes, J. D. Novak, Res. Alt. Con. Sc., Handbook of Research on Science Teaching and Learning, (McMillan, New York, 177-210, 1994)

31. M. Z. Hashweh, J. Res. Sc. Teach., 25, 121-134 (1988)

32. J. D. Novak, Theory of Education, (Cornell University Press, Ithaca, NY, 1977)

33. D. R. Driver, Euro. J. Sc. Edu., 3, 93-101 (1981)

34. J. Kuiper, Int. J. Sc. Edu., 16, 279-292 (1994).

35. K. S. Taber, Edu. Chem., 36, 135-137 (1999)

36. A. Caramazza, M. McCloskey, B. Green, Cog., 9, 117-123 (1981)

37. L. Resnik, Sc. Edu., 64, 59-84 (1983)

38. A. Champagne, R. Gunstone, L, Klopfer, Res. Sc. Tech. Edu., 1, 173-183 (1983)

39. C. R. Sutton, Euro. J. Sc. Edu., 2, 107-120 (1980)

40. S. A. Southerland, E. Abrams, C. L. Cummins, J. Anzelmo, Sc. Edu., 85, 328-348 (2001)

41. J. K. Gilbert, R. J. Osborne, P. J. Fensham, Sc. Edu., 66, 623-633 (1982)

42. R. J. Osborne, B. F. Bell, J. K. Gilbert, J. Sc. Edu., 5, 1-14 (1983)

43. G. Hills, Proceedings of the International Seminar on Misconceptions in Science and Mathematics, (June Cornell University, New York, 245-256, 1983)

44. I. A. Halloun, D. Hestenes, A. J. Phys., 53, 10561065 (1985)

45. Y. Lee, N. Law, Int. J. Sc. Edu., 23, 111-149 (2001)

46. P. Preece, Euro. J. Sc. Edu., 6, 7-10 (1984)

47. S. B. Boujaoude, J. Res. Sc. Teach., 29, 687-699 (1992)

48. R. Good, J. Res. Sc. Teach., 28, 387 (1991)

49. C. S Carter, N. W. Brickhouse, J. Chem. Edu., 66, 223-225 (1989)

50. A. B. Champagne, L. E Klopfer, R.F. Gunstone, Edu. Psycho., 17, 31-53 (1982)

51. L. Pines, L. West, Sc. Edu., 70, 583-604 (1986)

52. S. Novick, J. Nussbaum, Sc. Edu., 62(3), 273-281 (1978)

53. B. Butts, R. Smith, Res. Sci. Educ., 17 (1), 192201 (1987)

54. M. J. S., T. J. Greenbowe, Res. Sci. Teach., 34 (4), 377-398 (1997)

55. T. Pinarbasi, M. Sozbilir, N. Canpolat, Chem. Educ. Res. Pract., 10 (4), 273-280 (2009)

56. C. Tanahoung, R. Chitaree, C. Soankwan, Eura. J. Phys. Chems. Edu., 2(2), 82-94 (2010)

57. E. Uzuntiryaki, Ö. Geban, Inst. Sc., 33(4), 311-339 (2005)

58. C. F. Herrmann-Abell, G. E. DeBoer, Chemistry Education Research and Practice, 12(2), 184-192 (2011)

59. D. D. Milenković, T. N. Hrin, M. D. Segedinac, S. Horvat, J. Sub. Did., 1(1), 3-12. (2016)

60. H. Özmen, J. Sc. Edu. Tech., 13(2), 147-159, (2004)
61. S. Hasan, D. Bagayoko, E. L. Kelley, Phys. Edu., 34(5), 294-299 (1999)

62. D. F. Treagust, Int. J. Sc. Edu., 10, 159-169 (1988)

63. Effendy, Ikatan Ionik dan Cacat-Cacat pada Kristal Ionik. (Malang: Bayumedia, 2008)

64. Ardiansah., Miskonsepsi Guru dalam Materi Ikatan Kimia pada SMA Negeri di Kabupaten Bengkayang Menggunakan Certainty of Response Index (CRI) (Unpublished undergraduate thesis, Tanjungpura University, Pontianak, Indonesia, 2014) 